\title{
Introducing the National Collaborating Centres for Public Health
}

\author{
Barbara Medlar, David Mowat, Erica Di Ruggiero, John Frank
}

A s part of the federal government's commitment to renew and strengthen public health across Canada, $6 \mathrm{Na}-$ tional Collaborating Centres for Public Health (NCCs) have recently been established. Their purpose is to make research on public health more relevant and understandable for individuals and organizations that could use this information in their day-to-day practices and in policy-making.

The 6 centres are located in regions across Canada. They all have a national mandate, but each also focuses on a specialized area in public health (Table I).

\section{Role of the NCCs}

The central function of the NCCs is to conduct environmental scans and synthesize scientific evidence into structured reviews and other summaries of current knowledge and best practices. There are existing resources of this kind internationally (e.g., the Cochrane Collaboration's Health Promotion and Public Health Field Web site [www.vichealth.vic .gov.au/cochrane/welcome/index.htm]). However, they tend not to be sufficiently tailored to the needs of Canadian frontline public health practitioners.

The NCCs' activities will support increased effectiveness of public health programs and policies; contribute to the training and mentoring of the public health workforce; facilitate the exchange of knowledge between experts and practitioners in public health; and ensure that this knowledge is more widely available for use by public health policy-makers, program managers and practitioners. The NCCs will produce information to help public health professionals improve their response to public health threats, chronic disease and injury, infectious diseases and health disparities. The centres will also identify gaps in public health knowledge that need to be addressed by academia, governments, public health practitioners, nongovernment organizations and research-funding agencies. A recent Canadian review lays out this process in detail. ${ }^{1}$

The NCCs will also bring together networks of relevant stakeholders to facilitate and support the use of evidenceinformed decision-making by public health professionals, policy-makers and the various governance structures for public health in Canada. Over time, this work will contribute to on an improved capacity of our national public health infrastructure to address its priorities and achieve its goals.

\section{Initial focus}

The NCCs will initially collaborate with established public health networks to conduct environmental scans regarding

\begin{tabular}{ll}
$\begin{array}{l}\text { Table 1: Specialized areas of the } 6 \text { National Collaborating } \\
\text { Centres for Public Health located across Canada }\end{array}$ \\
\hline Specialized area & \multicolumn{1}{c}{ Location; contact person } \\
\hline Environmental health & $\begin{array}{l}\text { BC Centre for Disease Control, } \\
\text { Vancouver; Dr. Ray Copes } \\
\text { (ray.copes@bccdc.ca) }\end{array}$ \\
\hline Aboriginal health & $\begin{array}{l}\text { University of Northern British } \\
\text { Columbia, Prince George; Margo } \\
\text { Greenwood (greenwom@unbc.ca) }\end{array}$ \\
Infectious diseases & $\begin{array}{l}\text { International Centre for Infectious } \\
\text { Diseases, Winnipeg; Dr. Alan Ronald } \\
\text { (aronald@icid.com) }\end{array}$ \\
Public health & $\begin{array}{l}\text { In progress; Barbara Medlar } \\
\text { (barbara_medlar@phac-aspc.gc.ca) }\end{array}$ \\
methodologies and tools & $\begin{array}{l}\text { Institut national de santé publique } \\
\text { du Québec, Québec; Dr. Denise } \\
\text { Kouri (denise.kouri@inspq.qc.ca) }\end{array}$ \\
Healthy public policy & $\begin{array}{l}\text { St. Francis Xavier University, } \\
\text { Antigonish, NS; Dr. Lars Hallstrom } \\
\text { (lhallstr@stfx.ca) }\end{array}$ \\
\hline Determinants of health
\end{tabular}

"who is doing what" in a given field; analyze and synthesize scientific evidence and best practices concerning key issues in public health; identify gaps in existing knowledge that are suitable for targeting future research; and identify and champion projects to address these gaps, which ideally should be joint ventures of public health researchers and users of this research.

In July 2006 the NCCs piloted their first annual "summer institute," which was targeted to NCC staff and focused on high-quality methodologies for evidence searching, synthesis and knowledge transfer, for public health applications within each centre. It was evaluated highly by those attending and may be made available to non-NCC staff in future summers. A key example of the methodologies featured would be the development of criteria for assessing the quality of published evidence of the effectiveness of community programs and policies that often cannot be feasibly studied in randomized trials, necessitating instead the use of quasi-experimental study designs for their evaluation. ${ }^{2}$

\section{Affiliation with the Public Health Agency of Canada}

The NCCs are being funded for 2005-2009 through the Public Health Agency of Canada (PHAC). PHAC will maintain an arms-length relationship with the centres. Each centre must 
provide a yearly work plan and year-end reports for transparency and accountability.

PHAC has created a national Advisory Council for the network of NCCs. The council, chaired by one of us (J.F.), is comprised of a dozen recognized public health experts from across Canada and abroad and will serve the following functions:

- Act as an advisory body to the PHAC with respect to suitable priorities for the NCC program

- Support the NCCs in knowledge synthesis, transfer and exchange

- Provide recommendations to PHAC on NCC work plans, in terms of the soundness of the methodologies and applicability to national and international public health priorities

- Provide public health expertise to assess NCC knowledge syntheses and related products, such as public health practice guidelines and Web-based decision aids.

Each centre will also have its own Advisory Board, national in scope, that will more fully represent the individual NCC's constituencies.

\section{Helping public health professionals and decision-makers}

Each NCC will draw on regional, national and international expertise. Each will also collaborate with, and complement the contributions of, other organizations in the Pan-Canadian Public Health Network. This formal network links all I3 provincial/territorial governments with PHAC and reports to the Conference of Federal/Provincial/Territorial Deputy Ministers of Health. By focusing on the needs of public health practice, the NCCs will facilitate knowledge sharing and help translate knowledge into practice at all levels of Canada's public health system.

Preliminary findings from recent environmental scans of 2 NCCs validate the need to synthesize scientific evidence into structured reviews and other summaries of current knowledge and best practices.

The NCC for Environmental Health (NCC-EH), based at the British Columbia Centre for Disease Control, has just completed an environmental scan of the use of evidence in environmental health practice and policy-making nationally. This scan involved a I-year process of interviewing 65 environmental health practitioners, employed in some 38 Canadian public health agencies' environmental health services, to determine their current needs and preferences for the syntheses and transfer of scientific evidence relevant to their work.

The results of the environmental scan show that Canada has a lack of surveillance data on environmental exposures and risk factors, which is a key gap in the development of evidencebased policy and practice in environmental health. Environmental health practitioners and policymakers are not able to cite a large body of evidence as the basis for most current environmental health programs in Canada, and there is relatively little systematic evaluation of the effectiveness of those pro- grams. The NCC-EH will address these gaps, with significant input from practitioners, policymakers and researchers.

The NCC for Healthy Public Policy (NCC-HPP) is located in Montréal and is hosted by the Institut national de santé publique du Québec. Quebec has been innovative in its approaches to public health and the promotion of healthy public policy. For example, under article 54 of its Public Health Act, the provincial health minister must assess the health impact of other ministries' public policies, and conversely other ministries must report to the health minister about policies with a potential health impact. Healthy public policy is also being addressed in other provinces. For example, British Columbia's Act Now strategy brings together an intersectoral focus of provincial ministries toward health goals. The NCCHPP will share experiences in healthy public policy from across Canada to improve knowledge, under its mandate to support public health practitioners and officers in building healthy public policy.

In its environmental scan, potential users of NCC-HPP products and activities indicated a need for the public health community to be more knowledgeable about the public policy process itself. The NCC-HPP will make scientific and other information more accessible, relevant and usable; it will communicate relevant research on specific health risks and related interventions; it will investigate and promote effective tools to assess the health impact of selected public policies; and it will examine the policy-making process itself. The current pilot project is about obesity, with a focus on public policy options. The NCC-HPP is also examining past experiences with public policy, including tobacco and child poverty, in order to inform current experience. And finally the NCC-HPP is investigating strategies for health impact assessment, from Canada and other countries, and will disseminate the information to the public health community.

Barbara Medlar is NCC Program Manager, Office of Public Health Practice, and David Mowat is Deputy Chief Public Health Officer, Public Health Practice and Regional Operations, Public Health Agency of Canada, Ottawa, Ont.; Erica Di Ruggiero is Lecturer, Public Health Sciences, University of Toronto, and Associate Director, Canadian Institutes of Health Research (CIHR) Institute of Population and Public Health, Toronto, Ont.; John Frank is Professor, Public Health Sciences, University of Toronto, and Scientific Director, CIHR Institute of Population and Public Health, Toronto, Ont.

\section{REFERENCES}

I. Kiefer L, Frank J, Di Ruggiero E, et al. Fostering evidence-based decision-making in Canada: examining the need for a Canadian population and public health evidence centre and research network. Can J Public Health 2005;96:II-Irg.

2. Briss PA, Zaza S, Pappaioanou M, et al. Developing an evidence-based Guide to Community Preventive Services - methods. Task Force on Community Preventive Services. Am J Prev Med 2000;18(I Suppl):35-43.

Correspondence to: Barbara Medlar, NCC Program Manager, Office of Public Health Practice, Public Health Agency of Canada, I3o Colonnade Rd., AL 650IH, Ottawa ON KIA oKg; barbara_medlar@phac-aspc.gc.ca 